\title{
Irreversibility line and thermally activated flux flow in Micro- bridges of high-temperature superconductor
}

\author{
Ahmed Abou El Hassan ${ }^{1 *}$, Ahmed Taoufik ${ }^{1}$, Abdelaziz Labrag ${ }^{1,2}$, ,Mustapha Bghour ${ }^{1}$,Habiba El Hamidi ${ }^{l}$,Youssef Ait \\ Ahmed $^{l}$, Ahmed Tirbiyine ${ }^{2}$, and Hassan El Ouaddial. \\ ${ }^{1}$ Equipe des Matériaux Supraconducteurs, Université Ibn Zohr, Faculté des Sciences, BP: 8106, Agadir, Morocco \\ ${ }^{2}$ Université Ibn Zohr, Faculté des Sciences Appliquées, Route Nationale $N^{\circ} 10$ cité Azrou, Ait Melloul, Morocco
}

\begin{abstract}
We have studied the electrical resistivity as a function of temperature in Micro-bridges of $\mathrm{YBa}_{2} \mathrm{Cu}_{3} \mathrm{O}_{7-\delta}$ deposited by laser ablation on the $\mathrm{SrTiO}_{3}$ substrate face, around superconducting transition region in different magnetic fields. The activation energy $\mathrm{U}_{0}$ was determined and discussed using the Arrhenius relation. The irreversibility line $\mathrm{B}_{\text {irr }}$ and the upper critical field $\mathrm{B}_{\mathrm{c} 2}$ were obtained using $10 \%$ and $90 \%$ criteria of the normal-state resistivity value from $\rho(\mathrm{T})$ curves. A phase diagram of the studied sample is constructed showing the $\mathrm{Tg}$ glass line and a very broad vortex-liquid phase regime.
\end{abstract}

\footnotetext{
* Corresponding author:ahmed.abouelhassan@edu.uiz.ac.ma
} 


\section{Introduction}

The vortex dynamics in type II superconductors is of great interest and is the subject of much work. Experimental, theoretical and also simulation work indicate that these systems can have new dynamic phases and transitions between different flow regimes depending on the driving force that tends to set the vortex lattice in motion [1].

YBCO is one of the most interesting superconductors as its upper critical magnetic field and critical current density is quite large among HTSC. Many researchers have studied their electrical transport properties dependent on the magnetic field of hightemperature superconductors. As an example of transport properties, the electrical resistivity versus temperature $\rho(T)$ is strongly influenced by the application of magnetic field [2-9].

In this paper, we studied the dependence of the activation energy of different samples of $\mathrm{YBa}_{2} \mathrm{Cu}_{3} \mathrm{O}_{7-\delta}$ film as a function of the magnetic field and the temperature. An accepted method for probing this dependence is to measure the resistive transition in various magnetic fields applied and the determination of activation energy using the conventional Arrhenius relationship. The activation energy $\mathrm{U}_{0}$ values can be directly deduced from the slope of the Arrhenius curve. The resistivity curves allowed to identify a vortex glass (VG) phase and to obtain the value of the glass transition temperature $T_{g}$. A phase diagram of the studied samples was determined as a function of the evolution of the vortex-glass transition temperature $T_{g}$.

\section{Experimental procedure}

The sample used is in this work is a film of $\mathrm{YBa}_{2} \mathrm{Cu}_{3} \mathrm{O}_{7-\delta}$ deposited at $750^{\circ} \mathrm{C}$ on a $\mathrm{SrTiO}_{3}$ substrate by pulsed laser deposition. This film contains three samples of different geometries, each with a form of micro-bridge (width $\times$ length): $10 \mu \mathrm{m} \times 575 \mu \mathrm{m}$; $50 \mu \mathrm{m} \times 575 \mu \mathrm{m} ; 100 \mu \mathrm{m} \times 300 \mu \mathrm{m}$. The studied film was developed in the GREYC laboratory in France by Professor L. Méchin. Below are the conditions of samples preparation:

- Holder substrate temperature $\mathrm{T}=700^{\circ} \mathrm{C}$ (corresponding to a real substrate temperature of about $750^{\circ} \mathrm{C}$ ).

- $\mathrm{O} 2$ dynamic pressure during the deposit: $\mathrm{P}\left(\mathrm{O}_{2}\right)=0.5 \mathrm{mbar}$.

- Laser: $220 \mathrm{~mJ} / 3 \mathrm{~Hz}$.

- Speed: $0.06 \mathrm{~nm} / \mathrm{shot}$ (200 nm for 3000 shots).

- The cooling system is formed by a plateau for 30 minutes at $500^{\circ} \mathrm{C}$ and a pressure of $700 \mathrm{mbar}$.

- Target-substrate distance is $5 \mathrm{~cm}$.

It should be noted that deposit conditions of $\mathrm{YBa}_{2} \mathrm{Cu}_{3} \mathrm{O}_{7-\delta}$ depend on the deposit structure used. They are obviously similar but, for example, the temperatures and the pressures of deposit cannot be directly compared because their values depend on the geometry of the furnace, the position of the thermocouple compared to the substrate.

\section{Results and discussion}

\subsection{Temperature dependence of resistivity}

Figure 1 represents temperature dependence of the resistivity for the micro-bridges of $\mathrm{YBa}_{2} \mathrm{Cu}_{3} \mathrm{O}_{7-\delta}$ :(a) $10 \mu \mathrm{m} \times 575 \mu \mathrm{m}$, (b) $50 \mu \mathrm{m} \times 575 \mu \mathrm{m}$ and (c) $100 \mu \mathrm{m} \times 575$ $\mu \mathrm{m}$ near the superconducting transition Tc region at $\mathrm{B}=0,2$ and $7 \mathrm{~T}$, the field is oriented parallel to the $\mathrm{c}-$ axis ( $\mathrm{B} / / \mathrm{c})$. From the figures, two important behaviours have been observed. In zero magnetic field, the prepared samples exhibit a sharp transition to zero resistivity at critical temperature Tc and the sharpness of the transition is proportional to the degree of interconnectivity of grains [2,4]. The observed effect indicates a better quality of the prepared samples. By applying the magnetic field, the transition is broadened remarkably with the increase of the magnetic field.
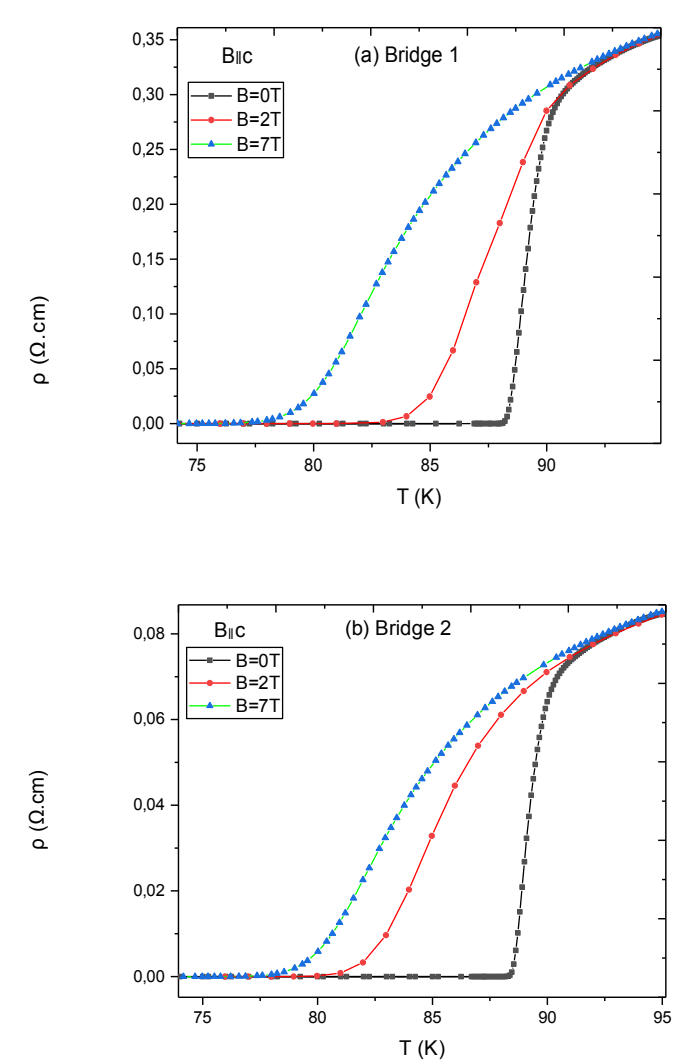


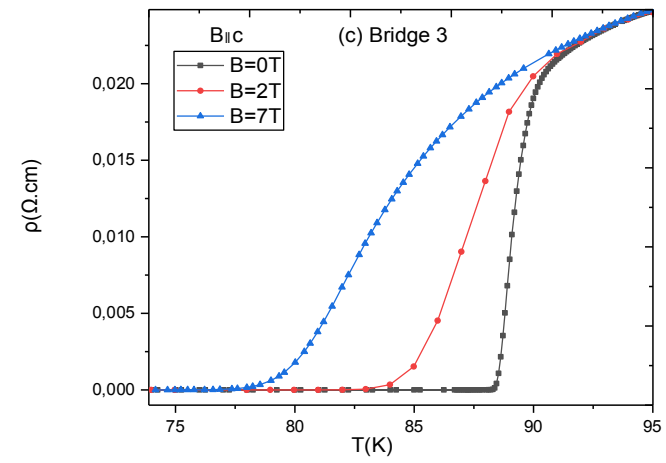

Fig.1. Temperature dependence of the resistivity for the micro-bridges $\mathrm{YBa}_{2} \mathrm{Cu}_{3} \mathrm{O}_{7-\delta}$ : (a) $10 \mu \mathrm{m} \times 575 \mu \mathrm{m}$, (b) 50 $\mu \mathrm{m} \times 575 \mu \mathrm{m}$, (c) $100 \mu \mathrm{m} \times 300 \mu \mathrm{m}$ at different applied fields and the current of $100 \mu \mathrm{A}$.

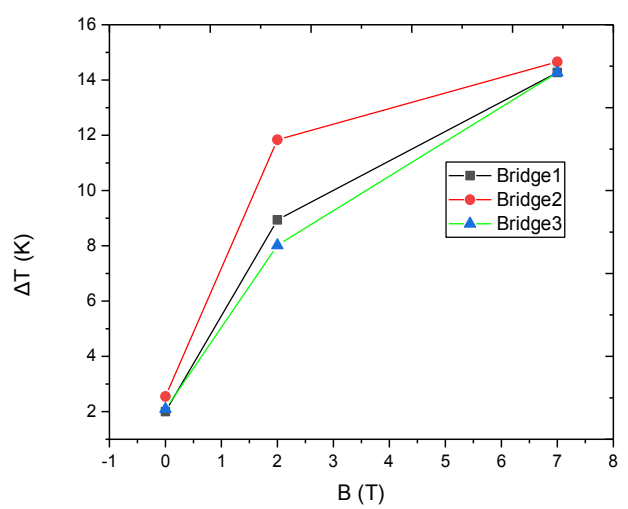

Fig.2. Evolution of the width of resistive transition $\Delta \mathrm{T}=\mathrm{T}_{\mathrm{c}}$, onset $-\mathrm{T}_{c}$, offset for different micro- bridges of $\mathrm{YBa}_{2} \mathrm{Cu}_{3} \mathrm{O}_{7-\delta}$

Table 1.The values of critical transition temperatures $\left(\mathrm{T}_{\mathrm{c} \text { onset }}\right.$ and $\left.\mathrm{T}_{\mathrm{coffset}}\right)$ and the temperature width $(\Delta \mathrm{T})$ for the microbridges $\mathrm{YBa}_{2} \mathrm{Cu}_{3} \mathrm{O}_{7-\delta}$ : (a) $10 \mu \mathrm{m} \times 575 \mu \mathrm{m}$, (b) $50 \mu \mathrm{m} \times 575 \mu \mathrm{m}$, (c) $100 \mu \mathrm{m} \times 300 \mu \mathrm{m}$ at different applied fields and the current of $100 \mu \mathrm{A}$.

\begin{tabular}{|l|l|l|l|}
\hline B & \multicolumn{1}{|c|}{ 0T } & \multicolumn{1}{|c|}{ 2T } & 7T \\
\hline Bridge1 & & & \\
$\mathrm{T}_{\mathrm{c}, \text { onset }}(\mathrm{K})$ & 90,30 & 91,95 & 91.82 \\
$\mathrm{~T}_{\mathrm{c}, \text { offset }}(\mathrm{K})$ & 88,30 & 83,01 & 77,55 \\
$\Delta \mathrm{T}(\mathrm{K})$ & 2,00 & 8,94 & 14,27 \\
& & & \\
\hline Bridge2 & 90,96 & 91,86 & 92,24 \\
$\mathrm{~T}_{\mathrm{c}, \text { onset }}(\mathrm{K})$ & 88,41 & 80,02 & 77,63 \\
$\mathrm{~T}_{\mathrm{c}, \text { offset }}(\mathrm{K})$ & 2,55 & 11,84 & 14,66 \\
$\Delta \mathrm{T}(\mathrm{K})$ & & & \\
\hline Bridge3 & 90,50 & 90,98 & 91,88 \\
$\mathrm{~T}_{\mathrm{c}, \text { onset }}(\mathrm{K})$ & 88,41 & 82,96 & 77,50 \\
$\mathrm{~T}_{\mathrm{c}, \text { offset }}(\mathrm{K})$ & 2,09 & 8,02 & 14,37 \\
$\Delta \mathrm{T}(\mathrm{K})$ & & & \\
\hline
\end{tabular}

As shown in Table 1 and Figure 2, for each sample, $\mathrm{T}_{\mathrm{c}}$, offset goes to lower values on increasing the magnetic field, resulting in a wider resistive transition $\Delta \mathrm{T}(\Delta \mathrm{T}=$ $\left.\mathrm{T}_{\mathrm{c}, \text { onset }}{ }^{-} \mathrm{T}_{\mathrm{c}, \text { offset }}\right)[2,10]$. The width $\Delta \mathrm{T}$ of superconductingtransition temperatures of the micro bridges' samples in a $7 \mathrm{~T}$ magnetic field appears to be nearly $14 \mathrm{~K}$. This effect is owed to the looseness of superconducting current paths.
Indeed, the larger number of grain boundaries and weak bonds among superconducting grains is, the wider $\Delta \mathrm{T}$ will be $[10,11]$. The tailing behaviour is known to be correlated with the high thermal energy of vortices and the disorders in the percolation path among grains owing to different directions in polycrystalline compounds [3]. This leads to the weakening of flux pinning strength and as a result, a more resistive state occurs $[1,2]$.

\subsection{Activation energy}

The transition region broadening under different magnetic fields can be examined in terms of activation energy of the vortex according to the law of Arrhenius [12-14]:

$$
\rho(B, T)=\rho_{0} e^{\frac{-U(B, T)}{K_{B} T}}
$$

Where $\rho_{0}$ is the normal resistivity, $U(B, T)$ is the activation energy for flux creep that depends on the temperature and magnetic field and $\mathrm{kB}$ is the Boltzmann constant. For the case of classical flux creep, where $U>>k_{B} T$, the activation energy should not depend on temperature and the resistivity behaves as[2,14]:

$$
\rho(B, T)=\rho_{0} e^{\frac{-U_{0}}{K_{B} T}}(2)
$$

Under this assumption, we can obtain the relation:

$$
\ln \rho(B, T)=\ln \rho_{0}-\frac{U_{0}(B)}{K_{B} T}(3)
$$

From this relation, $\ln \rho$ is linear to $1 / \mathrm{T}$, which is called an Arrhenius relation. The activation energy $\mathrm{U}_{0}$ values can be directly deduced by calculating the slope of each curve in the low resistivity regime presented in Figure 3 and Table 2 [15].

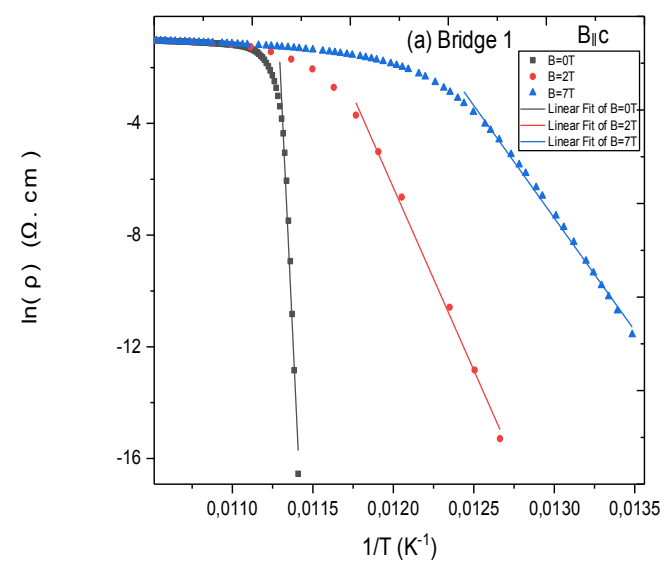



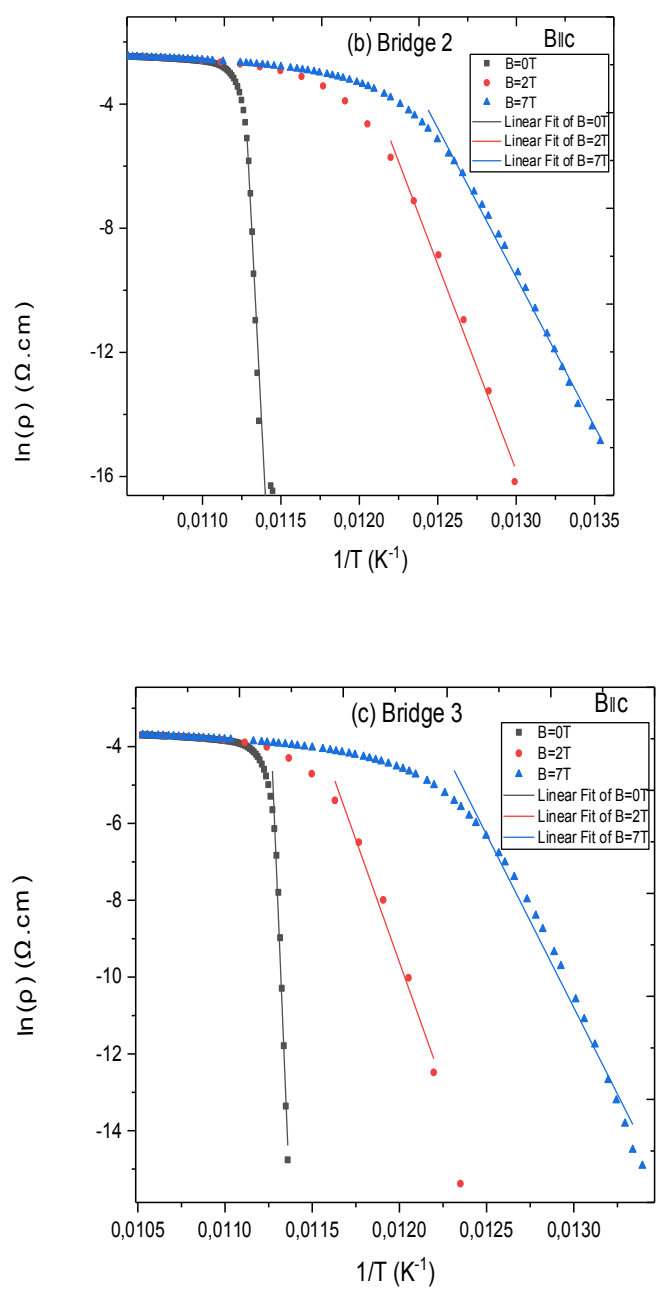

Fig.3. $\operatorname{Ln}(\rho)$ versus $1 / \mathrm{T}$ graphs of the micro- bridges of $\mathrm{YBa}_{2} \mathrm{Cu}_{3} \mathrm{O}_{7-\delta}$ : (a) $10 \mu \mathrm{m} \times 575 \mu \mathrm{m}$, (b) $50 \mu \mathrm{m} \times 575 \mu \mathrm{m}$, (c) $100 \mu \mathrm{m} \times 300 \mu \mathrm{m}$ at different applied fields and the current of $100 \mu \mathrm{A}$.

Table 2.Activation energy for the micro-bridges of $\mathrm{YBa}_{2} \mathrm{Cu}_{3} \mathrm{O}_{7-\delta}$ : (a) $10 \mu \mathrm{m} \times 575 \mu \mathrm{m}$, (b) $50 \mu \mathrm{m} \times 575 \mu \mathrm{m}$, (c) $100 \mu \mathrm{m} \times 300 \mu \mathrm{m}$ at different applied fields and the current of $100 \mu \mathrm{A}$.

\begin{tabular}{|l|l|c|c|}
\hline \multicolumn{4}{|l|}{ Activation energy (eV) } \\
\hline B & $\mathbf{0 T}$ & $\mathbf{2 T}$ & $\mathbf{7 T}$ \\
\hline Bridge1 & 10,52 & 1,12 & 0,69 \\
\hline Bridge2 & 8,52 & 1,14 & 0,82 \\
\hline Bridge3 & 9,54 & 1,09 & 0,77 \\
\hline
\end{tabular}

It is seen that the superconducting transition curve is fairly vertical and sharp at a $0 \mathrm{~T}$ magnetic field. As the applied magnetic field increases, the transition width expands. With the decline in slope of $\ln \rho(\mathrm{T})$ versus $1 / \mathrm{T}$, therefore the activation energy will decrease. The resistive transition in the Arrhenius plot appears curved. This curvature was explained first phenomenologically by Palstra et al. [16] who explained the field dependence of dissipative flux motion from the slope of the Arrhenius plot.

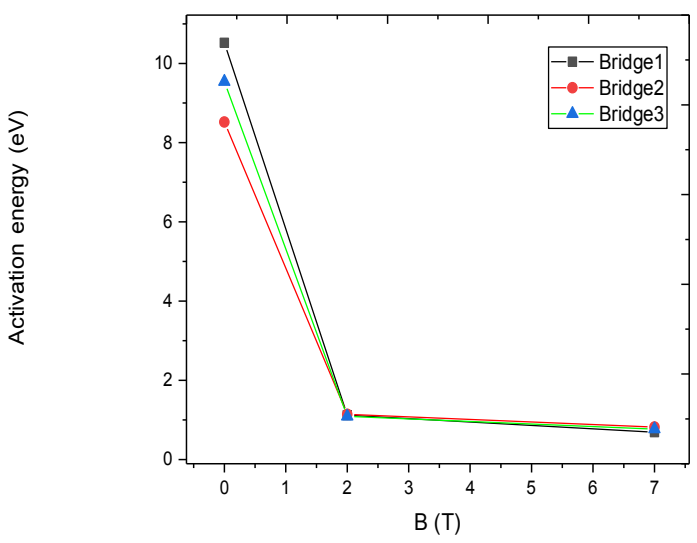

Fig.4. The change of the activation energy values of the micro- bridges of $\mathrm{YBa}_{2} \mathrm{Cu}_{3} \mathrm{O}_{7-\delta}$ with the applied magnetic field up to $7 \mathrm{~T}$

As seen in Figure 4, the decrease of the activation energy depending on the increasing magnetic field causes vortex motion easily.

\subsection{Irreversibility Line}

According to the vortex-glass theory, the resistivity in the flux-flow liquid region should approach zero as the temperature approaches the glass temperature $\mathrm{Tg}$ following a power-law behaviour[17,18]:

$$
\rho \propto\left(\mathrm{T}-T_{g}\right)^{s}(4)
$$

Where $\mathrm{s}$ is the exponent related to the vortex-glass correlation.

From this law we can use the relation:

$$
[d(\ln \rho / d T)]^{-1} \propto \frac{T-T_{g}}{s}(5)
$$

The temperature indicating the vortex-glass phase $\mathrm{T}_{\mathrm{g}}$ transition obtained from $\mathrm{T}$-axis intercept of $[d(\ln \rho / d T)]^{-1}$ versus $T$ plot $[19,20]$.

As shown in Figure 5, the estimated vortex glass transition temperature $\mathrm{T}_{\mathrm{g}}$ for different magnetic fields is shown in Table 3 . 

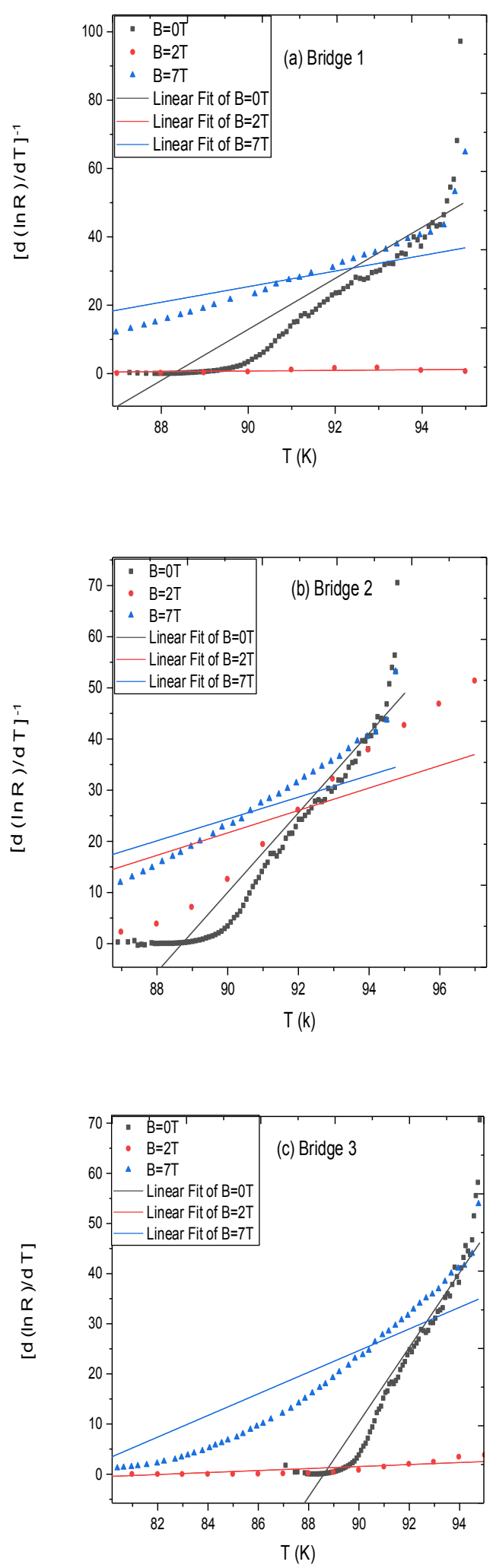

Fig.5. $d(\ln R) / d(1 / T)$ as a function of temperature in different magnetic fields: (a) $10 \mu \mathrm{m} \times 575 \mu \mathrm{m}$, (b) $50 \mu \mathrm{m} \times 575 \mu \mathrm{m}$, (c) $100 \mu \mathrm{m} \times 300 \mu \mathrm{m}$ at different applied fields and the current of $100 \mu \mathrm{A}$.

Table 3.The values of vortex-glass temperature for the micro-bridges of $\mathrm{YBa} 2 \mathrm{Cu} 3 \mathrm{O} 7-\delta$ : (a) $10 \mu \mathrm{m} \times 575 \mu \mathrm{m}$, (b) $50 \mu \mathrm{m} \times 575 \mu \mathrm{m}$, (c) $100 \mu \mathrm{m} \times 300 \mu \mathrm{m}$ at different applied fields and the current of $100 \mu \mathrm{A}$.

\begin{tabular}{|l|c|c|c|}
\hline \multicolumn{4}{|l|}{ vortex-glass temperature $\mathbf{T}_{\mathbf{g}}$} \\
\hline B & 0T & 2T & 7T \\
\hline Bridge1 & 88,34 & 82,36 & 79,12 \\
\hline Bridge2 & 88,82 & 80,21 & 78,55 \\
\hline Bridge3 & 88,70 & 82,38 & 78,82 \\
\hline
\end{tabular}

The $B_{\text {irr }}$ and $B_{c 2}$ are estimated from the resistivity versus the applied magnetic field curves. As it is well known from the literature [5,8], at various magnetic fields, the Birr and $\mathrm{Bc} 2$ are defined as the fields where the temperature-dependent resistance is $\rho\left(B_{c 2}, T\right)=$ $90 \% \rho_{n}$ and $\left(B_{\text {irr }}, T\right)=10 \% \rho_{n}$, where $\rho n$ indicates the normal state resistance of the samples at Tc, onset. From Figure 1, the $\mathrm{Bc} 2$ and the Birr were determined by the usual criterion of $90 \%$ and $10 \%$ of the normal state resistivity, respectively. The obtained values are tabulated in Table 4.

Table 4. $\mathrm{B}_{\text {irr }}, \mathrm{B}_{\mathrm{c} 2}$ and $\mathrm{T}$ values from magneto resistivity measurement for the micro-bridges of $\mathrm{YBa}_{2} \mathrm{Cu}_{3} \mathrm{O}_{7-\delta}:$ (a) $10 \mu \mathrm{m} \times 575 \mu \mathrm{m}$, (b) $50 \mu \mathrm{m} \times 575 \mu \mathrm{m}$, (c) $100 \mu \mathrm{m} \times 300 \mu \mathrm{m}$.

\begin{tabular}{|l|c|c|c|}
\hline B & 0T & 2T & 7T \\
\hline Bridge1 & & & \\
$T_{c 2,90 \%(K)}$ & 90,21 & 89,82 & 88,07 \\
$T_{i r r, 10 \%}(K)$ & 88,51 & 85,12 & 80.14 \\
\hline Bridge2 & & & \\
$T_{c 2,90 \%(K)}$ & 90,17 & 88,44 & 87,42 \\
$T_{i r r, 10 \%(K)}$ & 88,66 & 82,57 & 80,19 \\
\hline Bridge3 & & & \\
$T_{c 2,90 \%(K)}$ & 89,90 & 89,05 & 87,68 \\
$T_{i r r, 10 \%}(K)$ & 88,65 & 85,16 & 80,19 \\
\hline
\end{tabular}

We finally display in figure 6 the phase diagram constructed from values of $\mathrm{T}_{\mathrm{g}}(\mathrm{B}), \mathrm{T}_{\text {irr }}(\mathrm{B})$ and $\mathrm{T}_{\mathrm{c} 2}(\mathrm{~B})$ obtained for our sample, showing the vortex glass, the irreversibility line, the vortex liquid and normal state $[6,21]$. The vortex liquid phase exists above vortex glass phase and is confined between $\mathrm{B}\left(\mathrm{T}_{\mathrm{g}}\right)$ and $\mathrm{B}_{\mathrm{c} 2}$. Though a clear vortex liquid phase is observed, as it is well known from the literature that $[21,22]$ for fields, $B$ $>\mathrm{B}_{\mathrm{cl}}$ there is a kind of competition between thermal fluctuations and the repulsive inter-vortex interaction. As the temperature increases, the thermal fluctuations dominate resulting in the formation of vortex liquid phase. 


\section{Conclusions}
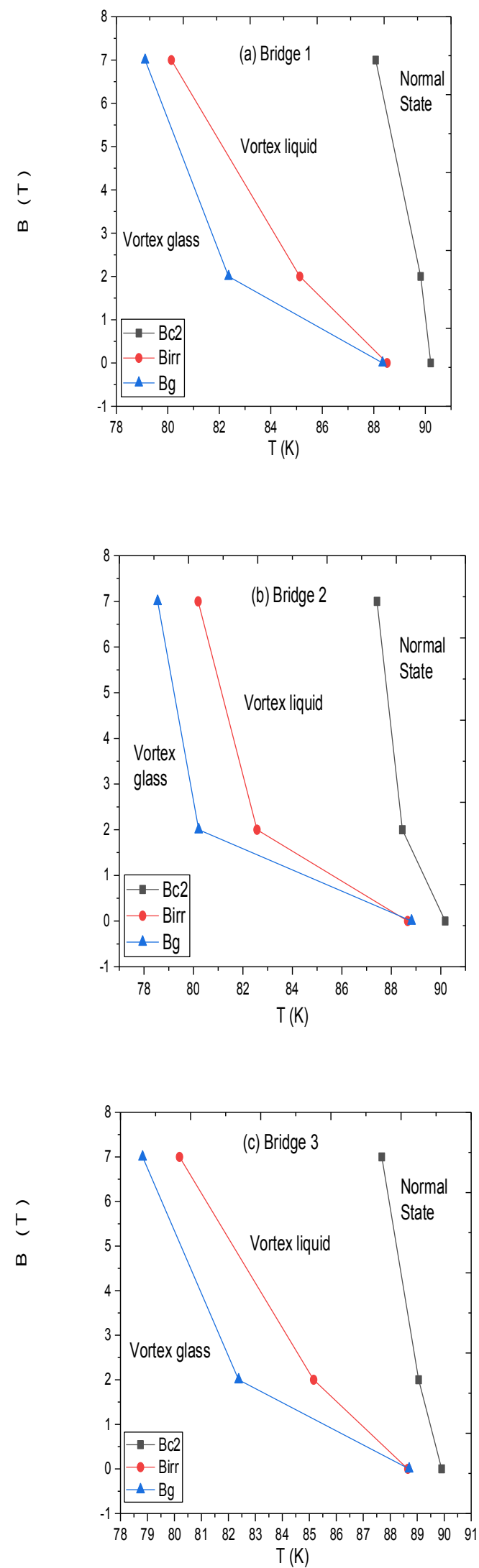

Fig.6 .Magnetic phase diagram obtained from this work for the micro-bridges of $\mathrm{YBa}_{2} \mathrm{Cu}_{3} \mathrm{O}_{7-\delta}:$ (a) $10 \mu \mathrm{m} \times 575 \mu \mathrm{m}$, (b) $50 \mu \mathrm{m} \times 575 \mu \mathrm{m}$, (c) $100 \mu \mathrm{m} \times 300 \mu \mathrm{m}$ at different applied fields and the current of $100 \mu \mathrm{A}$.
In conclusion, we report the magneto-resistivity of three micro bridges of samples $\mathrm{YBa}_{2} \mathrm{Cu}_{3} \mathrm{O}_{7-\delta}$. The broadening of the resistive transition under a magnetic field was observed and it can be described in the frame of the flux motion mechanism. From magnetoresistivity measurements, the activation energy $\mathrm{U}_{0}$, the upper critical field $\mathrm{B}_{\mathrm{c} 2}(0)$ and irreversibly field $\mathrm{B}_{\text {irr }}$ were calculated. The vortex phase diagram of $\mathrm{YBa}_{2} \mathrm{Cu}_{3} \mathrm{O}_{7-\delta}$ is presented using these results. A very broad vortex-liquid phase regime is found to exist in the vortex phase diagram of $\mathrm{YBa}_{2} \mathrm{Cu}_{3} \mathrm{O}_{7-\delta}$.

\section{Acknowledgements}

We gratefully thank Professor L. Méchin for providing the sample. We also gratefully acknowledge Professors C. Simon and A. Pautrat for their support.

\section{References}

1. G. Blatter, M. V. Feigel'man, V. B. Geshkenbein, A. I. Larkin, and V. M. Vinokur, Rev. Mod. Phys. 66, 1125 (1994).

2. S. Kurnaz, B. Çakır, and A. Aydıner, J Supercond Nov Magn 31, 3167 (2018).

3. D. Ahmad, W. J. Choi, Y. I. Seo, S. Seo, S. Lee, and Y. S. Kwon, Results in Physics 7, 16 (2017).

4. M. Hosseinzadeh, S. R. Ghorbani, and H. Arabi, Physica C: Superconductivity and Its Applications 548, 97 (2018).

5. Y. Z. Zhang, Z. A. Ren, and Z. X. Zhao, Supercond. Sci. Technol. 22, 065012 (2009).

6. A. Mariño, H. Sánchez, and H. Martínez, J Supercond Nov Magn 28, 391 (2015).

7. X. W. Zou, Z. H. Wang, J. L. Chen, and H. Zhang, Physica C 8 (2001).

8. T. Yang, Z. H. Wang, H. Zhang, J. Fang, Y. Nie, L. Qiu, and S. Y. Ding, Physica C 7 (2003).

9. X. Yi, C. Wang, Q. Tang, T. Peng, Y. Qiu, J. Xu, H. Sun, Y. Luo, and B. Yu, Supercond. Sci. Technol. 29, 105015 (2016).

10. E. Hannachi, Y. Slimani, A. Ekicibil, A. Manikandan, and F. B. Azzouz, J Mater Sci: Mater Electron 30, 8805 (2019).

11. M. R. Mohammadizadeh and M. Akhavan, 8 (n.d.).

12. M. Shahbazi, X. L. Wang, S. R. Ghorbani, S. X. Dou, and C. T. Lin, Physica C: Superconductivity and Its Applications 519, 60 (2015).

13. Y. Liu and X. G. Li, Journal of Applied Physics 99, 053903 (2006).

14. B. Sahoo, K. L. Routray, and D. Behera, Physica C: Superconductivity and Its Applications 562, 70 (2019). 
15. B. Sahoo, K. L. Routray, and D. Behera, Physica C: Superconductivity and Its Applications 562, 70 (2019).

16. T. T. M. Palstra, B. Batlogg, R. B. van Dover, L. F. Schneemeyer, and J. V. Waszczak, Phys. Rev. B 41, 6621 (1990).

17. S. Salem-Sugui, J. Mosqueira, A. D. Alvarenga, D. Sóñora, A. Crisan, A. M. Ionescu, S. Sundar, D. $\mathrm{Hu}$, S.-L. Li, and H.-Q. Luo, Supercond. Sci. Technol. 30, 055003 (2017).

18. S. Salem-Sugui Jr, A. D. Alvarenga, H.-Q. Luo, R. Zhang, and D.-L. Gong, Supercond. Sci. Technol. 30, 015007 (2017).

19. R. Kumar, A. Mitra, and G. D. Varma, Journal of Applied Physics 125, 193902 (2019).

20. A. El Tahan, G. Jakob, H. Adrian, and L. Miu, Physica C: Superconductivity 470, 1 (2010).

21. S. Rajput, Cryogenics 83, 17 (2017).

22. M. P. A. Fisher, PHYSICAL REVIEW LETTERS 62, 4 (1989). 